\title{
DESENVOLVIMENTO DE PLACAS DE CELERON
}

\section{Karla Hikari Akutagawa', Caroline da Silva Neves², Celia Kimie Matsuda Nabi Assad Filho ${ }^{4}$}

\begin{abstract}
${ }^{1}$ Acadêmica do Curso de Engenharia de Produção Agroindustrial, Universidade Estadual do Paraná - Campus de Campo Mourão, Bolsista PIC - UNESPAR. karla.akutagawa@gmail.com

${ }^{2}$ Acadêmica do Curso de Engenharia de Produção Agroindustrial, Universidade Estadual do Paraná - Campus de Campo Mourão, Bolsista PIC/ Fundação Araucária - UNESPAR. caroline_neves09@hotmail.com

${ }^{3}$ Orientadora, Doutora, Mestre, Departamento de Engenharia de Produção Agroindustrial - UNESPAR. Professora Pesquisadora do GMPAgro (Grupo Multidisciplinar de Pesquisas Agroindustriais).celia_matsuda@hotmail.com

${ }^{4}$ Co-orientador, Mestre, Departamento de Engenharia de Produção Agroindustrial - UNESPAR. Professor Pesquisador do GMPAgro. nabiassadfilho@hotmail.com
\end{abstract}

\section{RESUMO}

Esta pesquisa tem como objetivo desenvolver placas de Celeron. Que são chapas de laminado duro e denso, confeccionado com tecido de algodão em camadas intercaladas com resina fenólica e moldados em alta pressão e temperatura. O mesmo é utilizado para fins estruturais, pela sua resistência ao desgaste, cisalhamento e ao choque. Para tal, espera-se obter placas de qualidade semelhante ou idêntico as chapas de Celeron industriais, com baixo custo de produção, excelentes propriedades mecânicas, baixo coeficiente de atrito, baixo ruído, baixo peso especifico e um material fácil de ser usinado. Também espera-se apresentar um estudo comparativo de realidade com uma boa aceitação comercial, passível de utilização no desenvolvimento de produtos manufaturados inovadores e tecnologia nacional.

PALAVRAS_CHAVE: Chapas de Celeron; Resina Fenólica; Termofixo; Resistência.

\section{INTRODUÇÃO}

De acordo com Plastecno ([2019?]), a chapa de Celeron é um laminado duro e denso, fabricado com tecido de algodão que são colocados em camadas, que os mesmos são impregnados com resina fenólica e moldados em alta pressão a uma alta temperatura, resultando em um material bastante rígido e resistente.

De acordo com Santos, Veronica e Peçanha (2007), as resinas fenólicas são polímeros termorrígidos e totalmente sintéticos, que são utilizadas em diversas aplicações como adesivos para compensados, recobrimento de superfícies, matrizes na fabricação de compostos, para a indústria aeroespacial, automobilística, naval, espuma para isolamento térmico e acústico.

De acordo com Hiltz, Kuzak e Watkus (2001), a degradação da resina fenólica produz um material carbonizado que resulta em taxas muito baixas de espalhamento de chamas visto em comparação com resinas poliésteres.

O calor e a pressão quando aplicados simultaneamente às camadas gera uma reação química, ou seja, polimerização, que ocorre um aglomerando as camadas em uma massa sólida e compacta (VICK, 2017).

De acordo com a Vick (2017), por ser um produto termofixo é importante saber a sua definição do termo termofixo que é um material que após aplicado calor e pressão, tornase permanentemente rígido e não podendo posteriormente ser termo formado.

A placas de Celeron é utilizada para fins estruturais, por causa da sua alta resistência ao desgaste, ao cisalhamento e ao choque (IMPAKTTO, [2019?]).

As vantagens das placas de Celeron é o baixo peso específico, apresenta uma elevada resistência mecânica, usinagem fácil e ágil, um material elástico, consequentemente silencioso e livre de vibração, indeformável e resistente às formas dadas, não é higroscópico, resistente a água do mar, resistente ao óleo e ao álcool, resistente a ácidos e alcalinos de baixa concentração, resistente à corrosão, elevada 
tolerância térmica até $120^{\circ} \mathrm{C}$, resistente a mudanças bruscas de temperatura, não é inflamável, e é eletro-isolante para baixa tensão (INCOMPLAST, [2019?]).

A chapa de Celeron se diferencia de acordo com a malha de tecido utilizado, que varia de grosso, média, fino e extrafino. As placas de malha grossa são muito utilizadas na indústria, no entanto quanto mais fina for a malha, melhor será o seu acabamento na peça (VICK, 2017).

De acordo com Vick (2017), o laminado de Celeron se difere de acordo com a malha do tecido que é utilizado, que varia de extrafino, fino, médio e grosso. Cada malha tem a sua estrutura definida de acordo com o quadro 1:

Quadro 1: Tipos de Celeron

\begin{tabular}{|l|l|l|}
\hline Tipo de Celeron & Fios $/ \mathrm{cm}^{2}$ & Camadas $/ \mathrm{mm}$ de espessura \\
\hline Extrafino & 60 & 5,6 \\
\hline Fino & 45 & 3,1 \\
\hline Médio & 34 & 2,4 \\
\hline Grosso & 22 & 1,8 \\
\hline
\end{tabular}

Fonte: Vick, 2017, (adaptado).

Há uma linha especial de laminado industrial que é fabricada com reforço de tecido de fibras naturais inorgânicas, e resina fenólicas, em que tem uma grande importância industrial devido às propriedades físicas que não estão presentes em laminados de fibras orgânicas, como em mínima variação dimensional a temperaturas mais altas e durabilidade aliada a baixo coeficiente de atrito. Esses reforços são impregnados sobre pressão e calor em laminados com características desejáveis, as mais utilizadas são fenólicas, melamínicas e de epóxi, todas em forma liquida (VICK, 2017).

Os laminados industriais apresentam as seguintes propriedades (VICK, 2017):

- Mecânicas, que são laminados de tecidos selecionados para resistir a choque de cargas elevadas e ao desgaste, são utilizados tecidos mais finos que resultam numa chapa com maior precisão e melhor acabamento;

- Químicas, são laminados fenólicos que normalmente não são atacados com solventes como álcool, éter e derivados de refino de petróleo, apresentam resistência a baixa concentração de ácidos inorgânicos e ácidos orgânicos como cítricos, maleico, acético e lático, no entanto são atacados por ácidos oxidantes, como os álcalis fortes;

- $\quad$ Térmicas: são laminados em papéis ou tecidos de algodão que podem ser

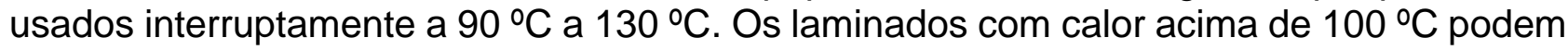
sofrer a sua ação;

- Físicas: é um material que apresenta alta elasticidade, sendo possível trabalhar com tolerâncias maiores, seu coeficiente térmico de expansão é de 3 a 5 vezes mais alto do que o aço;

- Elétricas: a sua resistência elétrica varia devido a configuração dos eletrodos, visto em que o isolante é ensaiado;

- Armazenamento: por ser um material significamente sensível a umidade, recomenda-se o armazenamento em lugares secos.

Dependendo da resina, o reforço empregado e o processo de laminação utilizada podem variar as propriedades dos laminados, visto que os valores de suas características são típicos. Já a escolha do laminado adequado para um uso específico é um problema de engenharia (VICK, 2017).

A aplicação da placa de Celeron varia conforme a aditivo utilizado, que pode variar em mecânica, grafitado ou elétrico. O mecânico pode ser aplicado para engrenagens anéis, polias, palhetas de bombas a vácuo e raspadores. O grafitado pode ser aplicado para buchas, mancais, espaçadores, guias de colunas ou até para peças que trabalha em 
ambientes onde exista dificuldade de acesso ou restrição a uso de lubrificantes. E o elétrico que pode ser aplicado para painéis e quadros elétricos, tirantes e porcas para transformadores elétricos (CELPAN, [2019?]).

Segundo Borges (2004), no Brasil são poucas as empresas que utilizam resinas fenólicas, que é um processo extremamente limitado, pois ainda não há tecnologia no país para o desenvolvimento destas resinas o que necessita de sua importação, o que torna o processo muito caro e em alguns casos inviável financeiramente.

\section{MATERIAIS E MÉTODOS}

Para alcançar os objetivos do projeto, ou seja, desenvolver placas de Celeron, serão realizadas as seguintes etapas:

- Revisão bibliográfica, que tem como objetivo coletar informações sobre os tipos de placas e chapas de Celeron fabricadas, as suas características e propriedades, as técnicas utilizadas na sua fabricação e materiais que são utilizados.

- Planejar metodologias, tipos de materiais e quantidade de materiais que serão necessários para a confecção das placas de Celeron.

- Para a confecção das placas de Celeron será desenvolvido uma prensa hidráulica com chapa aquecedora no Laboratório de Química Aplicada (LQA) e no Laboratório de Física Aplicada (LFA) na Universidade Estadual do Paraná - Campus de Campo Mourão. Assim auxiliando na sua montagem, serão realizados testes confeccionando placas de Celeron, analisando o comportamento da máquina de prensa hidráulica com chapa aquecedora e o resultado das primeiras amostras se atendem as características e os tipos das placas de Celeron que são comercializadas no mercado, com esses resultados será possível ajustar e evitar possíveis defeitos e problemas.

- Para a confecção das placas de Celeron será necessário utilizar e comprar tecidos de algodão, resinas fenólicas e desmoldante.

- Para os testes será confeccionado a placa de Celeron de malha média.

- Para esse tipo de placa de Celeron será utilizado malha média, de 25 a 35 fios $/ \mathrm{cm}^{2}$.

- Processo de confecção da placa de Celeron:

- Serão confeccionas em uma forma de ferro de tamanho de $30 \mathrm{~cm} \times 30 \mathrm{~cm}$.

- Será usado um desmoldante na forma para que a placa não grude e facilitando a sua retirada da forma.

- O tecido de algodão e a resina fenólica serão colocadas em camadas na forma, que impregnará laminada a alta temperatura $\left(120{ }^{\circ} \mathrm{C}\right.$ a $\left.130 \stackrel{\circ}{\circ} \mathrm{C}\right)$ e pressão por meio da prensa hidráulica com chapa aquecedora, por um intervalo de tempo que será definido conforme a confecção das amostras.

- A pressão irá variar com o tipo de placa que será confeccionada, sendo elas, malha média, fina e extrafina.

- Depois de dado o intervalo de prensa, a forma será deixada em descanso para ser desinformada.

- Após desinformada a placa será analisada quanto ao seu desempenho, de acordo com este ensaio:

- Ensaio mecânico de resistência à flexão ou resistência à tração na flexão, em placas que serão realizados em conformidade com a NBR 12775:1992.

\section{RESULTADOS E DISCUSSÕES}

Com o desenvolvimento deste projeto de pesquisa, espera-se a confecção de placas de Celeron de malha média a fim de obter placas de qualidade semelhante ou idêntica as 
placas e chapas de Celeron industriais com excelentes propriedades mecânicas, baixo coeficiente de atrito, baixo ruído, baixo peso especifico e um material fácil de ser usinado. Espera-se que esta pesquisa traga benefícios expressivos, tornando o processo de produção com baixo custo de produção e resultando em boa aceitação comercial, ou seja, passíveis de utilização no desenvolvimento de produtos manufaturados inovadores e tecnologia nacional.

\section{RESULTADOS ESPERADOS}

A pesquisa está em andamento, por isso não foram alcançados os resultados desejados, no entanto, é importante salientar que os próximos passos será a confecção das placas de Celeron de malha média, e a realização de testes, a fim de analisar a sua resistência, visto que já foi realizado um levantamento bibliográficos acerca da teoria necessária para o desenvolvimento da pesquisa.

\section{REFERÊNCIAS}

ABNT - Associação Brasileira de Normas Técnicas. NBR - Norma Brasileira Registrada 10. 004. Resíduos Sólidos: Classificação. Rio de Janeiro, 2004.

ABNT - Associação Brasileira de Normas Técnicas. NBR 12775:1992. Rio de Janeiro.

BORGES, Sandro Gasparetto. Síntese e caracterização de resinas fenólicas líquidas do tipo novolaca aplicáveis no processo de pultrusão. 2004. Trabalho para obtenção do título de Mestre em Engenharia (Mestre em engenharia) - Universidade Federal do Rio Grande do Sul, Porto Alegre, 2004. Disponível em:

https://www.lume.ufrgs.br/bitstream/handle/10183/29362/000456883.pdf?sequence=1. Acesso em: 21 mar. 2019.

CELPAN. Chapa de Celeron. [S. I.], [2019?]. Disponível em:

https://www.celpan.com.br/borracha/celeron/chapa. Acesso em: 15 mar. 2019.

IMPAKTTO. Chapa de Celeron. São Paulo - SP, [2019?]. Disponível em: http://www.impaktto.com.br/chapa-celeron.php. Acesso em: 15 mar. 2019.

INCOMPLAST. CELERON. . [S. I.], [2019?]. Disponível em: https://incomplast.com.br/celeron/ Acesso em: 25 ago. 2019.

Hiltz J.A.; Kuzak S.G., Waitkus P.A.. Appl. Polym. Sci. 2001.

PLASTECNO. Chapas de Celeron. [S. I.], [2019?]. Disponível em:

https://plastecno.com.br/produto/chapa_de_celeron.php. Acesso em: 16 mar. 2019.

SANTOS , Alessandra M. dos; CALADO, Verônica M. A.; PEÇANHA, Ricardo P. ESTUDO DO CICLO DE CURA DE RESINAS FENÓLICAS TIPO RESOL. Anais do 90 Congresso Brasileiro de Polímeros, [S. I.], 2007. 9o Congresso Brasileiro de Polímeros.

VICK. Revisão 2.3. [S. I.], 27 out. 2017. Disponível em:

https://www.vick.com.br/datasheets/datasheet-celeron.pdf. Acesso em: 18 mar. 2019. 